Minutisphaerales (Dothideomycetes, Ascomycota): a new order of freshwater ascomycetes including a new family, Minutisphaeraceae, and two new species from North Carolina, USA

By: Huzefa A. Raja, Tamam El-Elimat, Nicholas H. Oberlies, Carol A. Shearer, Andrew N. Miller, Kazuaki Tanaka, Akira Hashimoto, Jacques Fournier

Raja, H.A., El-Elimat, T., Oberlies, N.H., Shearer, C.A., Miller, A.N., Tanaka, K., Hashimoto, A., Fournier, J. 2015. Minutisphaerales (Dothideomycetes, Ascomycota): a new order of freshwater ascomycetes including a new family, Minutisphaeraceae, and two new species from North Carolina, USA. Mycologia. 107,4: 845-62. doi: 10.3852/15-013.

Made available courtesy of Mycological Society of America: http://dx.doi.org/10.3852/15$\underline{013}$

***(C) Mycological Society of America. Reprinted with permission. No further reproduction is authorized without written permission from Mycological Society of America. This version of the document is not the version of record. Figures and/or pictures may be missing from this format of the document. $* * *$

\title{
Abstract:
}

Minutisphaera is a recently established genus of freshwater Dothideomycetes characterized by small, globose to subglobose or apothecioid, erumpent to superficial, brown ascomata; fissitunicate, eight-spored, ovoid to obclavate asci; and 1-2-septate, clavate to broadly fusiform, hyaline to pale brown ascospores with or without a gelatinous sheath and filamentous appendages. The genus currently contains two species: M. fimbriatispora, the type species, and M. japonica. The higher-level phylogenetic relationship of Minutisphaerawithin the Dothideomycetes currently is unresolved. To establish the phylogenetic position of Minutisphaera within the Dothideomycetes and evaluate the phylogenetic affinities of newly collected Minutisphaera-like taxa, we sequenced three rDNA regions-18S, ITS1-5.8SITS2 (ITS) and 28S nuc rDNA, and a protein-coding gene, MCM7, for newly collected strains of Minutisphaera.Based on maximum likelihood and Bayesian analyses of a combined dataset (18S and 28S) composed of 167 taxa, a more refined dataset (28S and MCM7) comprising 52 taxa and a separate ITS dataset, and an examination of morphology, we describe and illustrate two new species of Minutisphaera. TheMinutisphaera clade was strongly supported within the Dothideomycetes with likelihood and Bayesian statistics but did not share phylogenetic affinities with any existing taxonomic group within the Dothideomycetes. We therefore establish a new order, Minutisphaerales, and new family, Minutisphaeraceae, for this monophyletic clade of freshwater ascomycetes. Chemical analysis of the organic extract M. aspera (G427) resulted in isolation and characterization of five known secondary metabolites, of which four were dipeptides (1-4) and one an aromatic polyketide (5). Conversely, two aromatic polyketides $(5,6)$ were isolated and identified from the organic extract of M. parafimbriatispora(G156-4). The isolated compounds were tested for their antimicrobial activity against an array of bacteria and fungi. Compound 6 showed promising activity against Staphylococcus 
aureus and Mycobacterium smegmatis with minimal inhibitory concentration values of 30 and 60 $\mu \mathrm{g} / \mathrm{mL}$, respectively.

Keywords: Aquatic | microfungi | submerged wood | systematics

Article:

***Note: Full text of article below 
Mycologia, 107(4), 2015, pp. 845-862. DOI: 10.3852/15-013

(C) 2015 by The Mycological Society of America, Lawrence, KS 66044-8897

\section{Minutisphaerales (Dothideomycetes, Ascomycota): a new order of freshwater ascomycetes including a new family, Minutisphaeraceae, and two new species from North Carolina, USA}

Huzefa A. Raja ${ }^{1}$

Tamam El-Elimat

Nicholas H. Oberlies

Department of Chemistry and Biochemistry, University of North Carolina, Greensboro, North Carolina 27402

Carol A. Shearer

Department of Plant Biology, University of Illinois, Urbana, Illinois 61801

Andrew N. Miller

Illinois Natural History Survey, University of Illinois, Champaign, Illinois 61820

Kazuaki Tanaka

Faculty of Agriculture and Life Sciences, Hirosaki University, Bunkyo-cho, Hiroskaki, Aomori 036-8561, Japan

Akira Hashimoto

The United Graduate School of Agricultural Sciences, Iwate University, 18-8 Ueda 3 chome, Morioka 0208550, Japan

Jacques Fournier

Las Muros, 09420 Rimont, France

Abstract: Minutisphaera is a recently established genus of freshwater Dothideomycetes characterized by small, globose to subglobose or apothecioid, erumpent to superficial, brown ascomata; fissitunicate, eight-spored, ovoid to obclavate asci; and 1-2septate, clavate to broadly fusiform, hyaline to pale brown ascospores with or without a gelatinous sheath and filamentous appendages. The genus currently contains two species: $M$. fimbriatispora, the type species, and M. japonica. The higher-level phylogenetic relationship of Minutisphaera within the Dothideomycetes currently is unresolved. To establish the phylogenetic position of Minutisphaera within the Dothideomycetes and evaluate the phylogenetic affinities of newly collected Minutisphaera-like taxa, we sequenced three rDNA regions-18S, ITS1-5.8SITS2 (ITS) and 28S nuc rDNA, and a protein-coding gene, MCM7, for newly collected strains of Minutisphaera. Based on maximum likelihood and Bayesian analyses of a combined dataset (18S and 28S) composed of 167 taxa, a more refined dataset (28S

Submitted 20 Jan 2015; accepted for publication 23 Apr 2015.

${ }^{1}$ Corresponding author. E-mail: haraja@uncg.edu and MCM7) comprising 52 taxa and a separate ITS dataset, and an examination of morphology, we describe and illustrate two new species of Minutisphaera. The Minutisphaera clade was strongly supported within the Dothideomycetes with likelihood and Bayesian statistics but did not share phylogenetic affinities with any existing taxonomic group within the Dothideomycetes. We therefore establish a new order, Minutisphaerales, and new family, Minutisphaeraceae, for this monophyletic clade of freshwater ascomycetes. Chemical analysis of the organic extract M. aspera (G427) resulted in isolation and characterization of five known secondary metabolites, of which four were dipeptides (1-4) and one an aromatic polyketide (5). Conversely, two aromatic polyketides $(5,6)$ were isolated and identified from the organic extract of M. parafimbriatispora (G156-4). The isolated compounds were tested for their antimicrobial activity against an array of bacteria and fungi. Compound 6 showed promising activity against Staphylococcus aureus and Mycobacterium smegmatis with minimal inhibitory concentration values of 30 and $60 \mu \mathrm{g} / \mathrm{mL}$, respectively.

Key words: Aquatic, microfungi, submerged wood, systematics

\section{INTRODUCTION}

The freshwater Dothideomycetes currently comprises 200 taxa $(32 \%)$ of ca. 622 ascomycetes reported from freshwater habitats (Shearer et al. 2014). In the past few years molecular phylogenetic studies have advanced our understanding of the systematics of freshwater Dothideomycetes (Inderbitzin et al. 2001, Schoch et al. 2009, Shearer et al. 2009, Hirayama et al. 2010, Ferrer et al. 2011, Suetrong et al. 2011, Hyde et al. 2013, Shearer et al. 2014). These studies have indicated that members of freshwater Dothideomycetes are (i) distinct from terrestrial Dothideomycete lineages, (ii) have adapted to freshwater habitats numerous times and (iii) most have phylogenetic affinites to the subclass Pleosporomycetidae. Only one taxon was described originally from freshwater (e.g. Mycosphaerella aquatica, Capnodiales) from submerged wood in a water cooling tower. Three other Mycosphaerella spp. reported from freshwater are related to the Dothideomycetidae (Shearer and Raja 2014), whereas only a few taxa are related to the 
Tubeufiales, Pleosporomycetidae (Boonmee et al. 2014). Despite the progress in our understanding of the systematics of Dothideomycetes (Hyde et al. 2013) and specifically freshwater Dothideomycetes (Shearer et al. 2009, Shearer et al. 2014) a number of newly described and/or previously reported taxa from freshwater are currently incertae sedis and their family and ordinal level positions within the Dothideomycetes remain obscure (Hyde et al. 2013). One such freshwater dothideomycete genus is Minutisphaera.

Minutisphaera Shearer, A.N. Mill \& Ferrer, typified by $M$. fimbriatispora Shearer, A.N. Mill \& Ferrer originally was described from submerged wood in freshwater habitats from USA (Ferrer et al. 2011). More recently a new species of Minutisphaera, $M$. japonica, was described and illustrated from Japan. This species is phylogenetically related to M. fimbriatispora based on rDNA sequence comparisons (Raja et al. 2013b). In addition to the newly found $M$. japonica, Raja et al. (2013b) also reported both morphological and molecular data for another Minutisphaera sp. (G156-1), which was sister to $M$. fimbriatispora and M. japonica. However, due to lack of material, the collection was not described as new and the authors indicated that further collections were necessary for study. In addition, the ordinal and familial position of Minutisphaera within the Dothideomycetes were unclear, although the Minutisphaera clade was strongly supported as being monophyletic in several molecular phylogenetic studies (Ferrer et al. 2011, Raja et al. 2013b, Shearer et al. 2014).

During our ongoing chemical mycological investigations of freshwater fungi in North Carolina, USA (Raja et al. 2013a, 2013b; El-Elimat et al. 2014a, 2014b), we found two additional Dothideomycetes taxa from freshwater habitats in the Piedmont region that shared morphological similarities with species of Minutisphaera. In particular we found a Minutisphaera-like taxon, which morphologically resembled a collection (G156-1) of Raja et al. (2013b) and warranted additional investigation. These newly found collections of Minutisphaera were morphologically similar to M. fimbriatispora and M. japonica but comprised combinations of characters in both ascus and ascospore morphology that precluded their inclusion in previously described Minutisphaera spp. Further we also collected a Minutisphaera-like taxon from France, which had morphological similarities to M. japonica. These new collections prompted a study of the molecular phylogenetic relationships of taxa within Minutisphaera, as well as the higher order phylogenetic relationship of Minutisphaera within the Dothideomycetes.
The goals of this study were to: (i) describe and illustrate the newly collected Minutisphaera spp. from freshwater habitats in the Piedmont region; (ii) place these newly collected taxa into a molecular phylogenetic framework by constructing a molecular phylogeny of Minutisphaera spp. using partial 18S, internal transcribed spacer regions (ITS) and partial 28S rDNA sequences, as well as the minichromosome maintenance protein complex 7 gene (MCM7), to better understand both the species as well as higherlevel relationships of Minutisphaera spp. within the Dothideomycetes; and (iii) screen isolates of newly collected species for secondary metabolites to determine the relationships between secondary products of both screened and unscreened isolates.

\section{MATERIALS AND METHODS}

Collection, morphological examination and fungal isolates.Methods of collection, isolation and morphological examination in this study were described by Shearer et al. (2004) and Raja and Shearer (2008). Sexual reproduction of pure culture isolates was stimulated in water cultures following methods outlined by Fallah and Shearer (2001). Measurements of micromorphological characters were made with Olympus cellSens software. Mean and standard deviation (SD) were calculated for asci and ascospores. Approximately 30 measurements were taken to calculate mean and SD. Cultures of newly obtained collections were deposited in Deutsche Sammlung von Mikroorganismen und Zellkulturen GmbH Inhoffenstraße (DSMZ), Germany. Duplicate copies of fungal cultures were deposited in the Department of Chemistry and Biochemistry Culture Collection at the University of North Carolina at Greensboro (UNCG). Voucher specimens of all newly collected taxa are deposited in the Illinois Natural History Survey Fungarium (ILLS).

DNA extraction, PCR amplification and sequencing.-For genomic DNA extractions, approximately $5 \mathrm{mg}$ mycelial powder was used; mycelial powder was obtained by grinding a small portion of the fungal colony in liquid nitrogen with a mortar and pestle. The powder was transferred to a bashing-bead tube with DNA lysis buffer provided by Zymo Research Fungal/Bacterial DNA Extraction Kit and vortexed vigorously $10 \mathrm{~min}$. DNA was extracted with procedures outlined in the Zymo Fungal/Bacterial DNA MicroPrep. All PCRs were run with an Applied Biosystems Veriti thermal-cycler. Partial fragments of 18 S and 28S D1D2 nuc rRNA genes were PCR amplified with puReTaq ${ }^{\mathrm{TM}}$ Ready-To-Go PCR beads (GE Biosciences Healthcare, New Jersey) according to Promputtha and Miller (2010). Primers NS1 and NS4 for 18S (White et al. 1990) and LROR and LR6 for 28S (Vilgalys and Hester 1990, Rehner and Samuels 1995) were used for PCR reactions in addition to $2.5 \mu \mathrm{L}$ BSA (bovine serum albumin, New England Biolabs, Ipswich, Massachusetts) and/or $2.5 \mu \mathrm{L}$ dimethyl sulfoxide (Fisher Scientific, Pittsburgh, Pennsylvania). The entire rDNA ITS region (ITS1-5.8S-ITS2) was PCR-amplified with primer combinations ITS5 and ITS4 (White et al. 1990, Gardes and 
Bruns 1993). MCM7, a single-copy gene, was amplified with primers Mcm 7-709for and Mcm7-1384rev (Schmitt et al. 2009) with thermo-cycler parameters outlined in Raja et al. (2011). The PCR products were run on an ethidium bromide-stained 1\% agarose gel (Fisher Scientific) along with a $1 \mathrm{~kb}$ DNA ladder (Promega) to estimate the size of the amplified band. PCR products were purified with a Wizard SV gel and PCR clean-up system (Promega). Sanger sequencing of the purified PCR products was performed at the University of Illinois Urbana-Champaign Biotechnology Center, as well as at Eurofins Genomics (http://www.operon.com/default.aspx) with the BigDye Terminator 3.1 cycle sequencing. Sequences were generated in both directions with the following sequencing primers: ITS = ITS5 and ITS4; 18S = NS1, NS4, NS3, NS4; 28S = LROR, LR3, LR3R, LR6; $M C M 7=$ Mcm 7709for, Mcm7-1384rev. Sequences were generated on an Applied Biosystems 3730XL high-throughput capillary sequencer. Sequences were assembled with Sequencher 5.2 (Gene Codes Corp.), optimized by eye and manually corrected when necessary. All newly obtained sequences were subjected to a GenBank BLASTn queries to verify identities.

Taxon sampling and phylogenetic analyses.-Three datasets were assembled for phylogenetic analyses: (i) a combined dataset composed of partial $18 \mathrm{~S}$ and $28 \mathrm{~S}$ nrDNA sequences from 167 taxa belonging to 19 families from 11 major orders of Pleosporomycetidae and Dothideomycetidae included in the Dothideomycetes (Schoch et al. 2009, Hyde et al. 2013) (Supplementary table I). Members of the Arthoniomycetes were included as outgroup taxa (Schoch et al. 2009). Most taxa included in this dataset were obtained from a molecular phylogenetic study of freshwater Dothideomycetes (Shearer et al. 2009, Raja et al. 2013b) and from recent studies of freshwater Dothideomycetes (Shearer et al. 2014).

(ii) The 52-taxa combined 28S-MCM7 dataset included all taxa of nonlichenized Dothideomycetes in GenBank for which MCM7 sequences are available (SUPPLEMENTARY TABLE II). This combined gene dataset was included and analyzed based on the results of Raja et al. (2011), which indicated that MCM7 gene was a valuable phylogenetic marker for both species as well as familial phylogenetic analyses within the Ascomycota, especially when used in association with the $28 \mathrm{~S}$ region. (iii) The ITS dataset comprising 16 sequences among which 14 strains belonged to Minutisphaera spp. with two additional strains included from GenBank. The two strains were included because they had high sequence similarity $(\geq 97 \%)$ and query coverage $(\geq 85 \%)$ with newly sequenced taxa in this study.

Multiple sequence alignments were generated following methods outlined by Shearer et al. (2009) and Raja et al. (2011). The program G blocks (Castresana 2000) 0.91b was used via the Gblocks server to remove ambiguous regions such as poorly aligned positions and divergent regions of the DNA alignment using default parameters. All datasets were evaluated for clade conflict using non-parametric bootstrap support (BS) based on methods outlined by
Lutzoni et al. (2004) and Raja et al. (2011). Because the topology of the clades obtained in the separate analyses did not show conflicting results in the separate 18S-28S and 28S-MCM7 datasets, sequences from each dataset were concatenated. Maximum likelihood (ML) analyses were performed on all three datasets with PHYML (Guindon et al. 2009) via the program Seaview 4.4.1 (Gouy et al. 2010). Model selection for ML analyses was accomplished with the program jModelTest 2.1.4 (Darriba et al. 2012) to obtain the best-fit model of nucleotide evolution for each dataset. The Akaike information criterion (AIC) (Posada and Buckley 2004) implemented in jModelTest selected the TIM3 $+\mathrm{I}+\mathrm{G}$ model for the $18 \mathrm{~S}-28 \mathrm{~S}$ dataset, the TIM23+I+G model for the 28S-MCM7 dataset and the TrNeF+I model for the ITS dataset. Using the appropriate models of evolution, PhyML analysis was run with six rate classes and invariable sites optimized along with combined nearest neighbor interchange (NNI) and subtree pruning and regrafting (SPR) tree search options in effect. For all three datasets BS (Felsenstein 1980) values were obtained with randomized accelerated maximum likelihood analysis with RAxML 7.0.4 (Stamatakis 2006) via the CIPRES Portal 3.3 (Miller et al. 2010) with the default rapid hill-climbing algorithm and GTR model employing 1000 fast bootstrap searches. Clades that received a $\mathrm{BS} \geq 70 \%$ were considered significant and robustly supported (Hillis and Bull 1993).

Bayesian inference (BI) employing a Markov chain Monte Carlo (MCMC) algorithm were performed on the datasets with MrBayes 3.12 (Huelsenbeck and Ronquist 2001, 2005) using the CIPRES Portal 3.3 as an additional measure of clade support. The selected models based on jModelTest 2.1.4 were implemented and constant characters were included, and four independent chains of Metropoliscoupled MCMC were run 100 million generations with trees sampled every 1000th generation, resulting in 100000 total trees. Independent BI analysis ensures that the same tree space is being sampled during each analysis and that the trees were not trapped in local optima. For BI, which was run with the combined 28S-MCM7 dataset, the data were partitioned based on gene as well as codon positions using flat priors and unlinked model parameters across partitions. The online program AWTY (Nylander et al. 2008) was used to compare the split frequencies of independent runs to ensure that the stationary phase was reached. The program TRACER 1.5 (Rambaut and Drummond 2009) was used to plot the log-likelihood scores against generation time to confirm that log-likelihood values had reached a stable equilibrium. To conservatively estimate that the log-likelihood values reached a stable equilibrium, the first 10000 trees that extended beyond the burn-in were discarded and the remaining 90000 trees were used to calculate the posterior probability (PP) in each analysis. Consensus trees were generated and viewed in PAUP 4.0b10 (Swofford 2002). Clades with a PP $\geq 95 \%$ were considered significant and strongly supported. All alignments are deposited in TreeBASE (www.treebase.org, submission number 16824).

ITS Barcoding of Minutisphaera spp.-The ITS region is the formally designated DNA barcode recommended for 
fungal species identification (Schoch et al. 2012). Uncorrected $\mathrm{p}$ distances were calculated in PAUP* for sequences obtained from the ITS region for 14 strains of Minutisphaera spp., which included the newly obtained fungi in this study. The $\mathrm{p}$ distances were obtained by dividing the number of nucleotide differences by the total number of nucleotides being compared. A cut-off proxy of $\geq 97 \%$ was applied as a criterion to designate similar species; therefore to be considered the same species based on ITS sequence comparison, the taxa being compared should have $\geq 97 \%$ sequence similarity (with $3 \%$ intraspecific variation or differences). ITS sequences were obtained from ex-type cultures so they can be designated as RefSeq Targeted Loci entries (Schoch et al. 2014) and be made available as references for future taxonomic and ecological studies of freshwater ascomycetes.

Fermentation, extraction and isolation.-G427: To six flasks, each containing a $50 \mathrm{~mL}$ liquid culture (2\% soy peptone, $2 \%$ dextrose and $1 \%$ yeast extract; YESD media) of fungal growth, grown approximately $21 \mathrm{~d}$ at room temperature, 60 $\mathrm{mL} \mathrm{1:1} \mathrm{MeOH} / \mathrm{CHCl}_{3}, 90 \mathrm{~mL} \mathrm{CHCl}_{3}$ and $100 \mathrm{~mL}$ water was added. Then the samples were stirred $2 \mathrm{~h}$, followed by vacuum filtration. The filtrates were combined and transferred into a separatory funnel. The bottom layer was drawn off into a round-bottom flask and was evaporated. The dried organic extract was reconstituted in $100 \mathrm{~mL} \mathrm{1:1} \mathrm{MeOH/}$ MeCN and $100 \mathrm{~mL}$ hexanes and transferred to a separatory funnel. The biphasic solution was shaken vigorously. The $\mathrm{MeOH} / \mathrm{MeCN}$ layer was evaporated under vacuum. The organic defatted extract $(48.1 \mathrm{mg})$ was subjected to preparative HPLC over a Phenomenex Gemini-NX $\mathrm{C}_{18}(5$ $\mu \mathrm{m} ; 250 \times 21.2 \mathrm{~mm}$ ) column using an isocratic system of 15:85 $\mathrm{CH}_{3} \mathrm{CN}_{-} \mathrm{H}_{2} \mathrm{O}$ (0.1\% formic acid) for $40 \mathrm{~min}$ at a flow rate of $21.24 \mathrm{~mL} / \mathrm{min}$ to yield six subfractions. Subfractions $3,4,5$ and 6 yielded compounds 1 (4.7 mg), 2 (1.2 mg), 3 (2.0 $\mathrm{mg})$ and $5(2.1 \mathrm{mg})$, which eluted at 14.6, 17.3, 22.2 and $25.7 \mathrm{~min}$, respectively. Subfraction 1 was subjected to semipreparative HPLC over a Phenomenex Gemini-NX $\mathrm{C}_{18}$ $(5 \mu \mathrm{m}, 250 \times 10.0 \mathrm{~mm})$ using an isocratic system of 10:90 $\mathrm{CH}_{3} \mathrm{CN}-\mathrm{H}_{2} \mathrm{O}(0.1 \%$ formic acid) at a flow rate of $4.72 \mathrm{~mL} /$ min to yield compound $4(1.1 \mathrm{mg})$, which eluted at $\sim 25.0$ min. On the other hand when the fungus was grown on a solid culture of rice for approximately $28 \mathrm{~d}$ at room temperature and extracted in a similar manner only compound 5 was detected.

G156-4: To two flasks, each containing a sample of $\sim 25 \mathrm{~g}$ rice with fungal growth, grown for approximately $28 \mathrm{~d}$ at room temperature, $60 \mathrm{~mL} \mathrm{1:1} \mathrm{MeOH} / \mathrm{CHCl}_{3}$ was added. Then the samples were chopped with a spatula and were shaken overnight $(\sim 16 \mathrm{~h})$ at $\sim 100 \mathrm{rpm}$ at room temperature. The samples were filtered with vacuum filtration, and the remaining residues were washed with $\mathrm{MeOH}$. To the filtrate $90 \mathrm{~mL}$ of $\mathrm{CHCl}_{3}$ and $150 \mathrm{~mL}$ water were added. The mixture was stirred $30 \mathrm{~min}$ and transferred into a separatory funnel. The bottom layer was drawn off into a round-bottom flask and was evaporated. The dried organic extract was reconstituted in $100 \mathrm{~mL} \mathrm{1:1} \mathrm{MeOH}$ / MeCN and $100 \mathrm{~mL}$ hexanes and transferred to a separatory funnel. The biphasic solution was shaken vigorously. The
$\mathrm{MeOH} / \mathrm{MeCN}$ layer was evaporated under vacuum. The organic defatted extract $(74.2 \mathrm{mg})$ was dissolved in $\mathrm{CHCl}_{3}$, adsorbed onto Celite 545, and fractionated via normalphase flash chromatography using a gradient solvent system of hexane- $\mathrm{CHCl}_{3}-\mathrm{MeOH}$ at a $18 \mathrm{~mL} / \mathrm{min}$ flow rate and 68.1 column volumes over $18.2 \mathrm{~min}$ to afford two fractions. Fraction 1 (39.5 mg) was subjected to preparative HPLC using a Phenomenex Gemini-NX $\mathrm{C}_{18}$ column and gradient system of 20:80-100:00 $\mathrm{CH}_{3} \mathrm{CN}-\mathrm{H}_{2} \mathrm{O}$ (0.1\% formic acid) over $15 \mathrm{~min}$ at a flow rate of $21.24 \mathrm{~mL} / \mathrm{min}$ to yield compounds $5(0.5 \mathrm{mg})$ and $6(0.2 \mathrm{mg})$, which eluted at 11.0 and $16.8 \mathrm{~min}$, respectively.

Marfey's analysis of 1-4.- The absolute configuration of the dipeptides (1-4) was determined by Marfey's analysis of the individual amino acids as reported by Ayers et al. (2012).

Antimicrobial assay.-Minimal inhibitory concentrations (MICs) of compounds 1-6 were measured against a panel of bacteria and fungi as described (El-Elimat et al. 2014a, 2014c). All measurements were duplicated.

\section{RESULTS}

Molecular study.-Twenty-two sequences, 5 18S, 4 ITS, $628 \mathrm{~S}$ and 7 MCM7, were generated (TABLE I). Because we did not find any significant topological conflicts between the tree topologies of individual genes, the $18 \mathrm{~S}$ and $28 \mathrm{~S}$ alignments (dataset I) as well as $28 \mathrm{~S}$ and MCM7 alignments (dataset II) were concatenated. The initial 167-taxa combined 18S28S alignment consisted of 3969 nucleotides. After excluding ambiguous regions, introns, and nucleotides from the $5^{\prime}$ and $3^{\prime}$ ends due to missing data in many sequences, the final 18S-28S alignment consisted of 2050 nucleotides. The initial 52-taxa combined 28S-MCM7 alignment consisted of 2066 nucleotides, which resulted in a final alignment of 1685 nucleotides when ambiguous regions and fragments of $5^{\prime}$ and $3^{\prime}$ ends were discarded from the final analyses. The MCM7 gene is a promising candidate for inferring reliable phylogenetic relationships across the Ascomycota (Aguileta et al. 2008, Schmitt et al. 2009, Raja et al. 2011). The ITS dataset for 14 strains of Minutisphaera spp. consisted of 691 nucleotides including the primer regions at the $5^{\prime}$ and $3^{\prime}$ ends. The two strains included in the alignment from GenBank, Pleosporales sp. 39g (JX244063) and Didymosphaeria sp. TS_04_050 (HQ713763), increased the alignment length to 1217 nucleotides. After the ends were trimmed and ambiguous regions excluded with Gblocks, the final ITS alignment contained 599 nucleotides.

PHYML analysis of the 167-taxa combined 18S and 28S genes produced a single most likely tree (FIG. 1). All taxa belonging to Minutisphaera grouped in a highly supported clade with $100 \%$ RAxML BS and 
TABLE I. Source of Minutisphaera used in this study and GenBank accession numbers for 18S, ITS, 28S and MCM7

\begin{tabular}{|c|c|c|c|c|c|c|}
\hline \multirow[b]{2}{*}{ Species } & \multirow[b]{2}{*}{ Isolate No. ${ }^{\mathrm{a}}$} & \multirow[b]{2}{*}{ Source $^{\mathrm{a}}$} & \multicolumn{4}{|c|}{ GenBank accession Nos. ${ }^{c}$} \\
\hline & & & $18 \mathrm{~S}$ & ITS & $28 \mathrm{~S}$ & $M C M 7$ \\
\hline Minutisphaera aspera & $\mathrm{G} 427-1 \mathrm{a}^{\mathrm{b}}$ & DSM 29478 & KP309999 & KP309989 & KP309993 & KP310008 \\
\hline Minutisphaera aspera & G427-1b & Raja and Oberlies & KP310000 & KP309990 & KP309994 & - \\
\hline Minutisphaera fimbriatispora & G155-1a & Raja and Oberlies & JX474865 & JX474874 & JX474859 & KP310007 \\
\hline Minutisphaera fimbriatispora & $\mathrm{A} 242-8 \mathrm{a}^{\mathrm{b}}$ & Shearer & HM196374 & - & HM196367 & - \\
\hline Minutisphaera fimbriatispora & A242-7c & Shearer & - & JX474871 & - & \\
\hline Minutisphaera fimbriatispora & A242-7d & Shearer & HМ196373 & JX474872 & HM196366 & - \\
\hline Minutisphaera japonica & JCM 18561 & MAFF 243473 & AB733432 & $\mathrm{AB} 733435$ & AB733438 & KP310005 \\
\hline Minutisphaera japonica & JCM 18562 & MAFF 243474 & $\mathrm{AB} 733433$ & $\mathrm{AB} 733436$ & AB733439 & KP310006 \\
\hline Minutisphaera japonica & JCM $18560^{\mathrm{b}}$ & MAFF 243475 & $\mathrm{AB} 733434$ & NR119419 & AB733440 & KP310004 \\
\hline Minutisphaera japonica & JF08056 & Jacques Fournier & - & - & KP309998 & - \\
\hline Minutisphaera parafimbriatispora & G156-1 $\mathrm{a}^{\mathrm{b}}$ & DSM 29479 & JX474866 & JX474875 & JX4748660 & KP310009 \\
\hline Minutisphaera parafimbriatispora & G156-1b & Raja and Oberlies & KP310001 & - & KP309995 & - \\
\hline Minutisphaera parafimbriatispora & G156-4a & DSM 29480 & KP310002 & KP309991 & KP309996 & - \\
\hline Minutisphaera parafimbriatispora & G156-4b & Raja and Oberlies & KP310003 & KP309992 & KP309997 & KP310010 \\
\hline Minutisphaera sp. & G156-2 & Raja and Oberlies & - & JX474876 & - & - \\
\hline Minutisphaera sp. & G156-2 & Raja and Oberlies & - & JX474877 & - & - \\
\hline
\end{tabular}

a Abbreviations: DSMZ, German Collection of Microorganisms and Cell Cultures, Braunschweig, Germany; G, University of North Carolina, Greensboro, Department of Chemistry and Biochemistry Fungal Culture Collection; JCM, Collection of Microorganisms, the Ministry of Agriculture, Forestry and Fisheries, Japan (MAFF); JF, Jacques Fournier, France.

b Type strains.

${ }^{\mathrm{c}}$ All accession numbers starting with KP3 were newly sequenced in this study.

significant 100\% Bayesian PP support within the Dothideomycetes. In the Minutisphaera clade there are four distinct subclades, namely A, B, C and D. Isolates of the newly collected species G427-1 (subclade D) received 99\% RAxML BS and 97\% Bayesian PP, while G156-1 and G156-4 (subclade C) received $68 \%$ RAxML BS but did not reveal significant Bayesian PP values. Previously described species of Minutisphaera (M. japonica; subclade B) received $88 \%$ RAxML BS along with a new isolate of M. japonica collected from France (this study), while M. fimbriatispora (subclade A) received significant RAxML BS and Bayesian PP support. PHYML analysis of the 52-taxa combined 28S-MCM7 genes produced a single most likely tree (FIG. 2). In this analysis the Minutisphaera clade received $100 \%$ RAxML BS and 100\% Bayesian PP support. All four subclades ( $M$. fimbriatispora, subclade A, $M$. japonica, subclade B, G156-1 and G156-4, subclade C, and G427-1, subclade D) received significant $(\geq 90 \%)$ RAxML BS and Bayesian PP clade support.

Among ITS sequences the average intraspecific variation between strains of Minutisphaera was $1.0 \%$, whereas the average interspecific difference between species of Minutisphaera was 8.0\% (data not shown). PHYML analysis of the ITS region for 14 strains of Minutisphaera with two strains from GenBank, which had high sequence similarity to members of Minutisphaera generated a single most likely tree (FIG. 3). The newly found strains of Minutisphaera (subclades C, D) had significant overall support (100\% BS, 99-100\% Bayesian PP). Two strains from GenBank (HQ713763, JX244063) in subclade F grouped with the 14 other Minutisphaera strains with significant support (100\% BS, $99-100 \%$ Bayesian PP).

Phylogenetic analyses of 167-taxa combined 18S and $28 \mathrm{~S}$ gene sequences (FIG. 1) as well as 52-taxa combined 28S-MCM7 gene sequences (FIG. 2) clearly indicate that the Minutisphaera clade is monophyletic with significant branch support (100\% BS and Bayesian PP) and does not belong to or group with any of the existing families and orders that were included in the phylogenetic analyses. Based on these results we establish a new order, Minutisphaerales, and new family, Minutisphaeraceae, for this currently exclusive freshwater Dothideomycetes clade.

In addition, the molecular phylogenetic analyses of all three datasets (FIGs. 1-3) clearly support the establishment of $M$. aspera and M. parafimbriatispora as new and separate taxa within the genus Minutisphaera. These placements are further corroborated by morphological data provided below. These taxa therefore are described and illustrated herein as new species. 


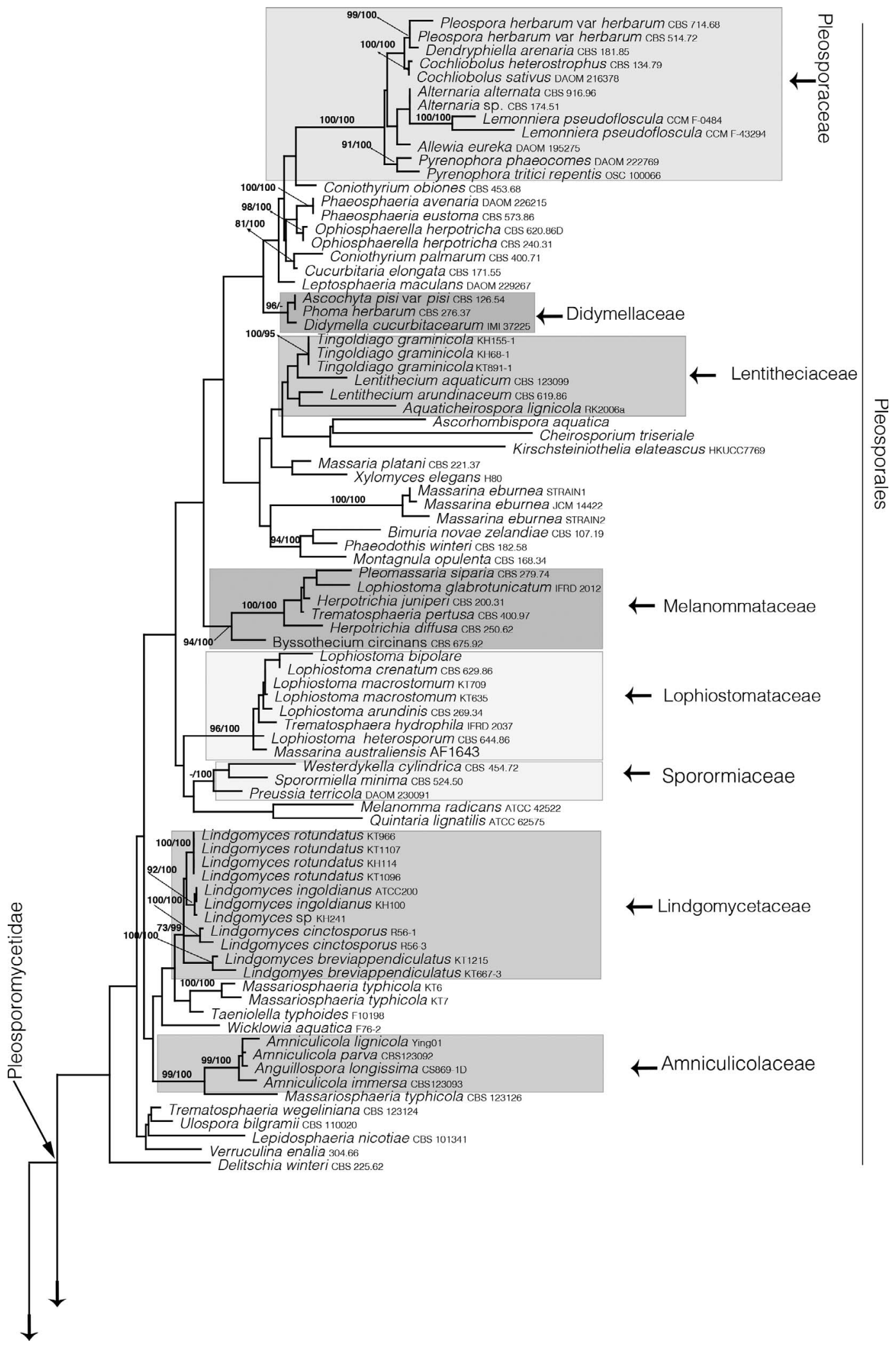

FIG. 1. Phylogram of the most likely tree $(-\operatorname{lnL}=24982.93)$ from a PHYML analysis of 167 taxa based on combined 18S and $28 \mathrm{~S}$ nrDNA (2050 bp). Numbers indicate RAxML bootstrap support values $\geq 70 \%$ based on 1000 replicates and significant Bayesian posterior probabilities $\geq 95 \%$. Members of the Arthoniomycetes were used as outgroup taxa. Newly established species, order and family are indicated in boldface on the right. Bar indicates nucleotide substitutions per site. 


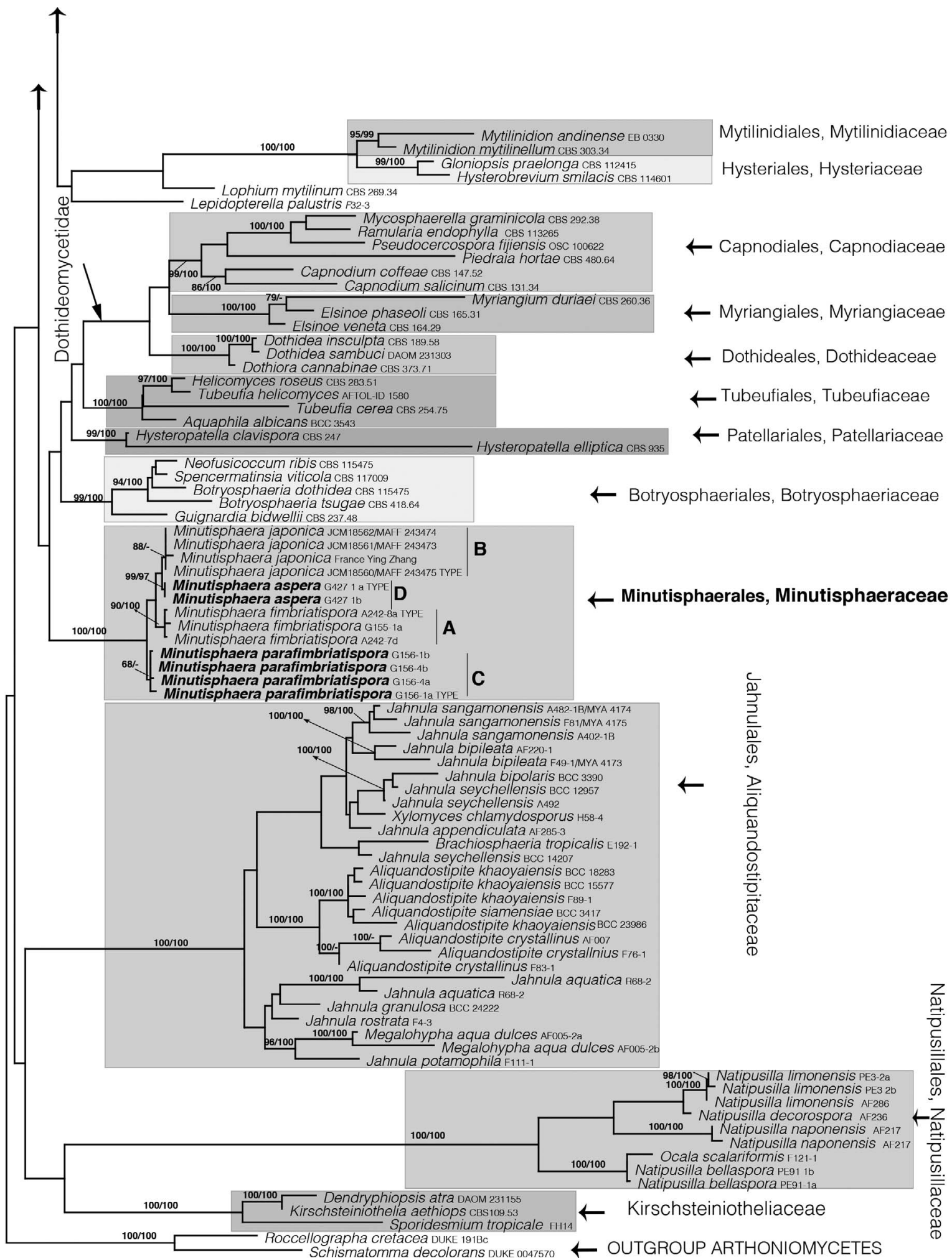

FIG. 1. Continued. 


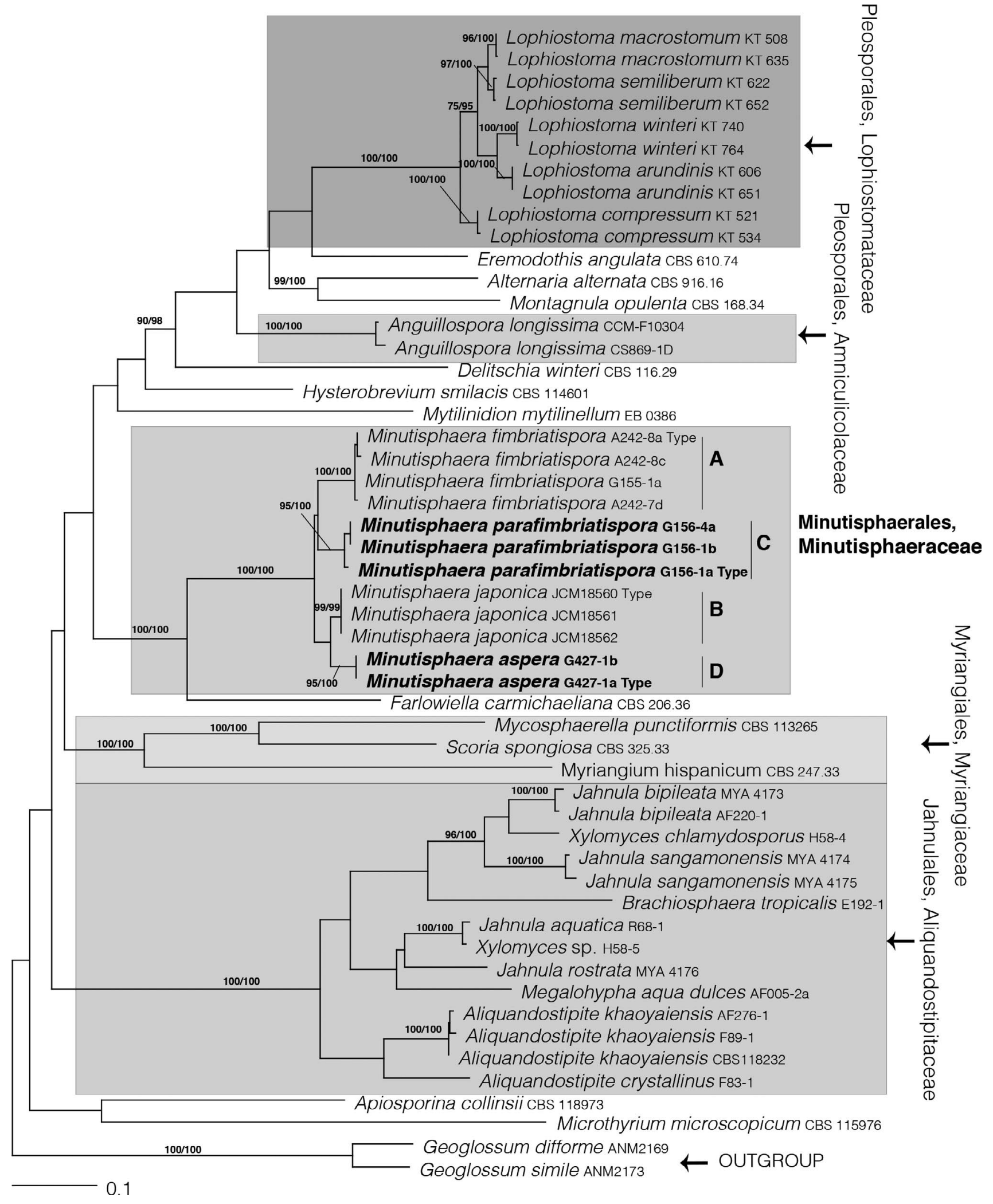

FIG. 2. Phylogram of the most likely tree $(-\ln L=17040.60)$ from a PHYML analysis of 52 taxa based on combined $28 \mathrm{~S}$ and MCM7 regions (1685 bp). (Support values as in FIG. 1). Newly described species, order and family are indicated in boldface. Bar indicates nucleotide substitutions per site. 


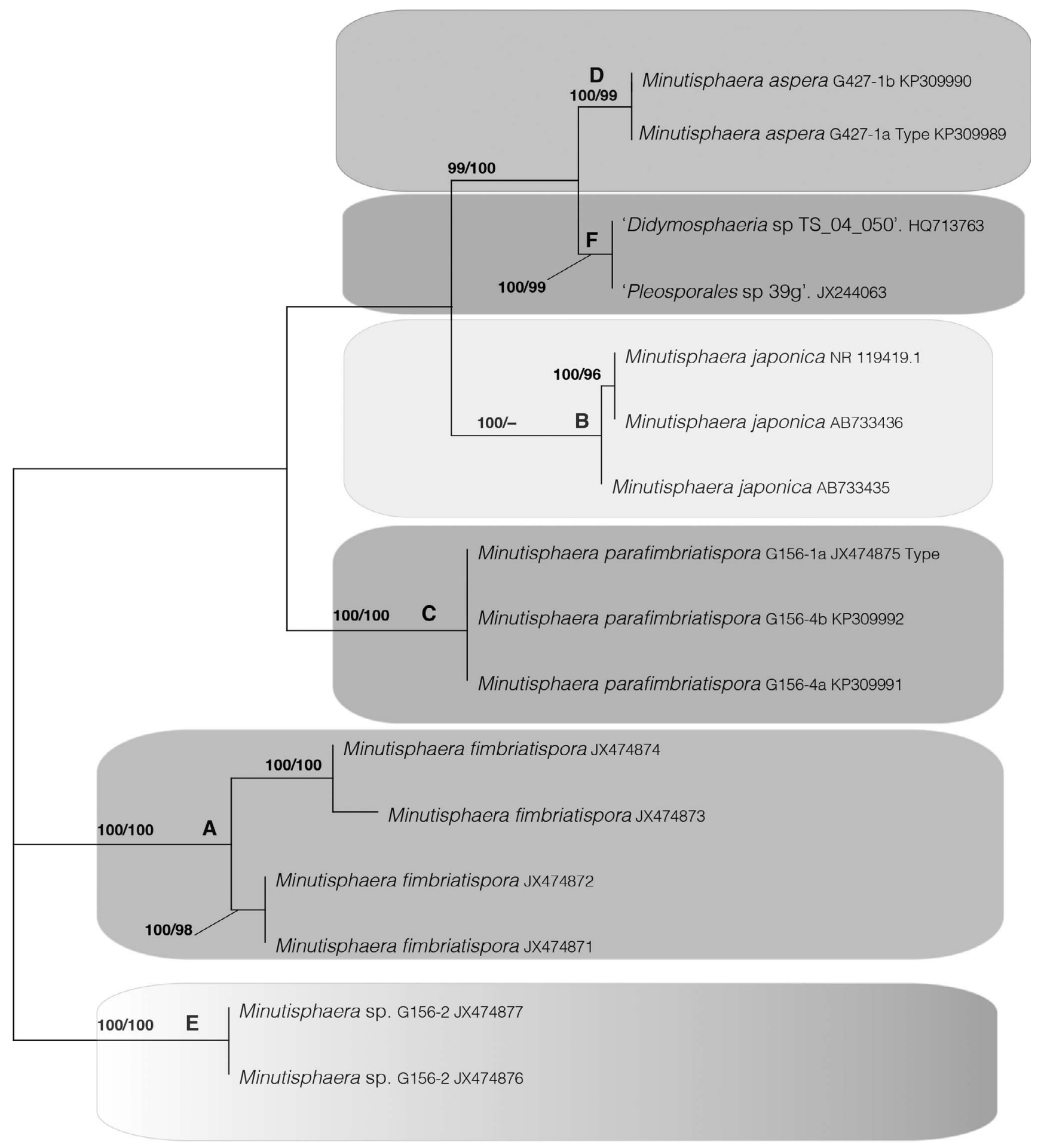

0.1

FIG. 3. Phylogram of the most likely tree $(-\operatorname{lnL}=1360.2)$ from a PHYML analysis of 14 strains of Minutisphaera spp. and two strains from GenBank based on ITS nrDNA (599 bp). (Support values as in FIG. 1.) Bar indicates nucleotide substitutions per site. 


\section{TAXONOMY}

Minutisphaerales Raja, Oberlies, Shearer \& A.N. Mill., ord. nov.

MycoBank MB811951

Type family. Minutisphaeraceae Raja, Oberlies, Shearer \& A.N. Mill

Ascomata small, pseudothecioid or apothecioid with irregularly curved, dark brown to black hyphallike structures around the ostiole. Pseudoparaphyses septate, with or without enlarged pigmented tips. Asci ovoid, obclavate to broadly cylindrical, fissitunicate, eight-spored. Ascospores clavate to broadly fusiform, smooth- or rough-walled, hyaline or pale brown, septate, with or without gelatinous sheath and with or without numerous filamentous appendages radiating around the mid-septum.

Minutisphaeraceae Raja, Oberlies, Shearer \& A.N. Mill., fam. nov.

\section{MycoBank MB811062}

Ascomata small, pseudothecioid or apothecioid, erumpent to superficial, brown, with an ostiole and irregularly curved, dark brown to black hyphal-like structures around the ostiole. Peridium thin-walled, composed of textura angularis to textura globosum. Pseudoparaphyses septate, with or without enlarged pigmented tips. Asci fissitunicate, eight-spored, ovoid to obclavate, lacking a stalk, rounded at apex. Ascospores clavate, fusiform to ellipsoidal, multiguttulate, smooth or rough-walled, hyaline or pale brown septate, with gelatinous sheath, with or without numerous filamentous appendages radiating around the mid-septum.

Type genus: Minutisphaera Shearer, A.N. Mill. \& A. Ferrer, Ferrer et al., Mycologia 103:415, 2011.

Minutisphaera aspera Raja, Oberlies, Shearer \& A.N. Mill., sp. nov. FIG. 4 MycoBank MB811063

Typification: USA. NORTH CAROLINA: Rockingham County, Piedmont Plateau, 36 27'42.1"N, $80^{\circ} 01^{\prime} 45.9^{\prime \prime} \mathrm{W}$, water $13 \mathrm{C}, \mathrm{pH}$, Big Beaver Island Creek, Madison, on submerged decorticated wood, 26 Apr 2013, H.A. Raja, and N.H. Oberlies G427-1 (holotype ILLS 72340). Ex-type culture DSM 29478, single ascospore isolate from holotype.

Etymology: aspera (L.), roughened, in reference to the verrucose ascospore wall.

Ascomata 235-480 $\mu \mathrm{m}$ diam, superficial, scattered, initially globose to subglobose, pseudothecioid when young, apothecioid at maturity, dark brown to black, membranous. Beak absent. Peridium composed of a single layer of dark brown angular cells; cells 7-11 $\times$
5-7 $\mu \mathrm{m}$, of textura angularis in surface view, with dark brown amorphous material deposited irregularly on the peridial surface, especially dense around the upper ostiolar region (FIGS. 4A-C). Hamathecium composed of cellular pseudoparaphyses, sparse in young ascomata, becoming abundant with age, hyaline, septate, filamentous (FIG. 4D). Asci 45-80 $\times$ 23-42 $\mu \mathrm{m}$ (mean and SD $=63 \pm 7.2 \times 31 \pm 1.3 \mu \mathrm{m}$, $\mathrm{n}=30)$, fissitunicate, subglobose to clavate, thickwalled at the apex, containing eight biseriate to multiseriate ascospores (FIG. 4E-G). Ascospores 24$33 \times 9-14 \mu \mathrm{m}$ (mean and $\mathrm{SD}=29 \pm 2 \times 11 \pm 1.2$ $\mu \mathrm{m}, \mathrm{n}=40)$, broadly fusiform when young becoming ellipsoidal with age, one-septate, primary septum median to submedian (0.50-0.53; average $0.51, \mathrm{n}=$ 40), septum hyaline and thin at first becoming thicker and darker in older ascospores, upper cell longer and wider than lower cell, ascospores hyaline when young, multiguttulate, (FIG. 4E-G), becoming dark brown and rough-walled with age; surrounded by an appressed, hyaline sheath with irregular margins in younger ascospores; in older ascospores sheath condensing and darkening to form a dark, appressed, verruculose ascospore wall covering (FIGS. 4H-J).

Culture characters: Colonies on PDA 30-40 mm diam after $21 \mathrm{~d}$ at $25 \mathrm{C}$ dark brown to gray with irregular margins. Older colonies on PDA appearing hyaline to cream colored with aerial mycelium.

Anamorph: None observed.

Habitat: On submerged wood in a freshwater stream.

Known distribution: USA (North Carolina). Notes: Minutisphaera aspera is morphologically similar to $M$. japonica in ascospore size and color; both species produce similar ascospores $(24-33 \times 9-14 \mu \mathrm{m}$ for $M$. aspera vs. 25-33 × 9-11 $\mu \mathrm{m}$ for M. japonica) that are hyaline when young becoming dark brown with age. However, the ascospores of M. aspera are surrounded by an appressed sheath, which appears condensed and deepens on older, brown ascospores to give a dark brown, verruculose appearance to the ascospore wall (FIG. 4). Although an amorphous sheath surrounds ascospores of $M$. japonica, the ascospore wall does not have a verruculose appearance. Additional collections of $M$. japonica examined from France during this study also provide support to this morphological observation. Another morphological feature that differs between the two species is the upper half of the ascospore, which in M. aspera is broader in comparison to $M$. japonica; the tips of the ascospores also differ with $M$. aspera having a wider apex, while $M$. japonica is more pointed and slightly curved. Molecular phylogenetic analyses clearly separate the two species into distinct monophyletic groups (FIGS. 1-3). 

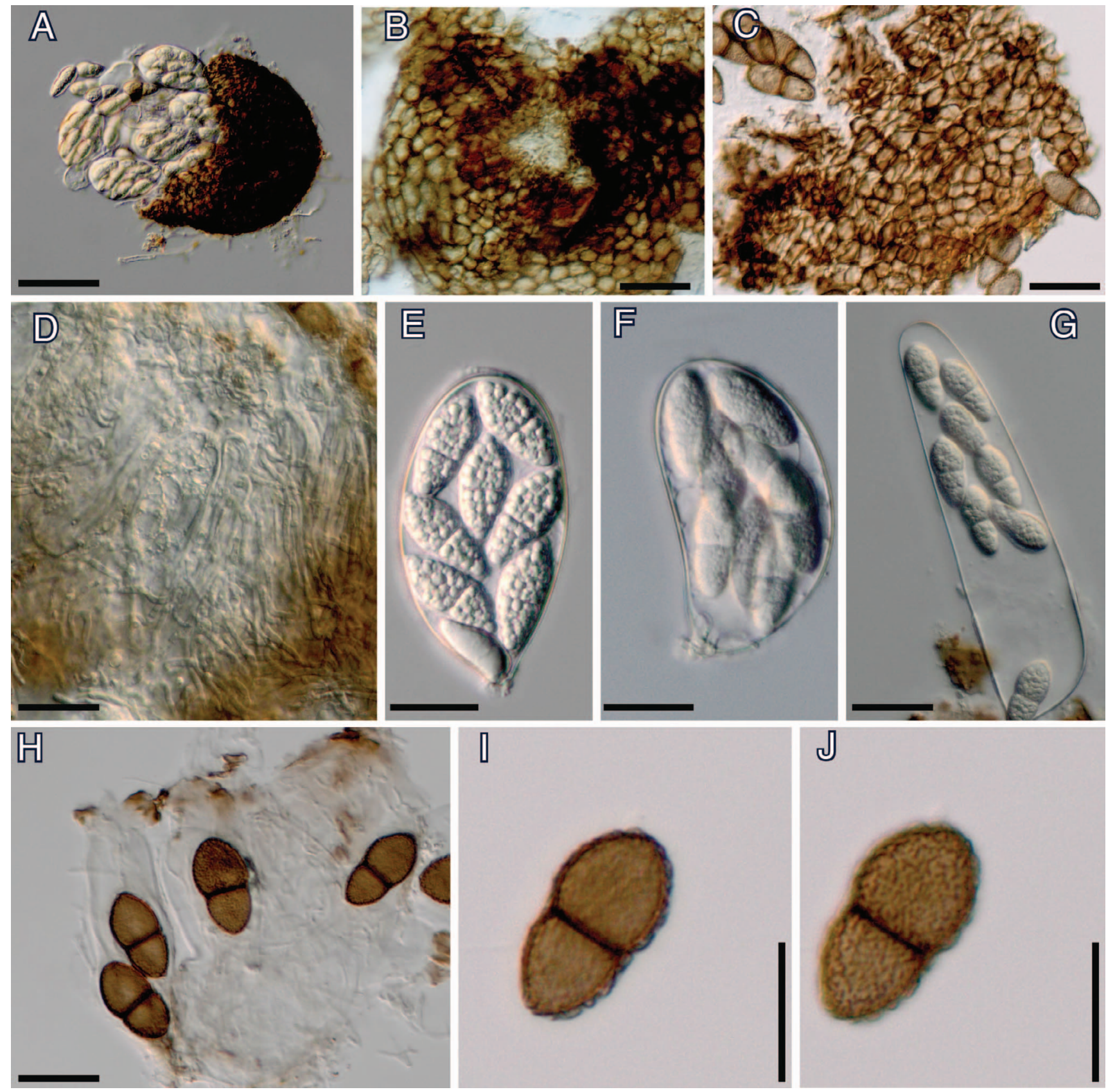

Fig. 4. Minutisphaera aspera (From HOLOTYPE. G427-1). A-C. Squash mounts of ascomata. D. Pseudoparaphyses. E, F. Asci. G. Ascus extending in water to shed ascospores. H-J. Ascospores (note rough wall of ascospore in I, J). Bars: A = 50 $\mu \mathrm{m}$; $\mathrm{B}-\mathrm{F}, \mathrm{I}, \mathrm{J}=20 \mu \mathrm{m} ; \mathrm{G}, \mathrm{H}=10 \mu \mathrm{m}$.

Minutisphaera parafimbriatispora Raja, Oberlies, Shearer \& A.N. Mill., sp. nov.

FIG. 5 MycoBank MB811064

Typification: USA. NORTH CAROLINA: Guilford County, Piedmont Plateau, Bur-Mil Park, Greensboro, swampy area behind Lake Brandt, $36^{\circ} 10^{\prime} 14.0^{\prime \prime} \mathrm{N}$, $79^{\circ} 52^{\prime} 06.0^{\prime \prime} \mathrm{W}$, on submerged decorticated wood, 20 Oct 2011, H.A. Raja, G156-1 (holotype ILLS 72341).
Ex-type culture: DSM 29479, single ascospore isolate from holotype.

Etymology: Named for its morphological resemblance to M. fimbriatispora; Gr. para $=$ near, to fimbriatispora .

Ascomata 160-170 $\mu \mathrm{m}$ high, 170-180 $\mu \mathrm{m}$ diam, black, superficial, scattered or in clusters, globose with a flattened apex that becomes collabent with age, apothecioid at maturity (FIG. 5A, B). Beak absent. Dark brown hyphae-like pigmented structures present 

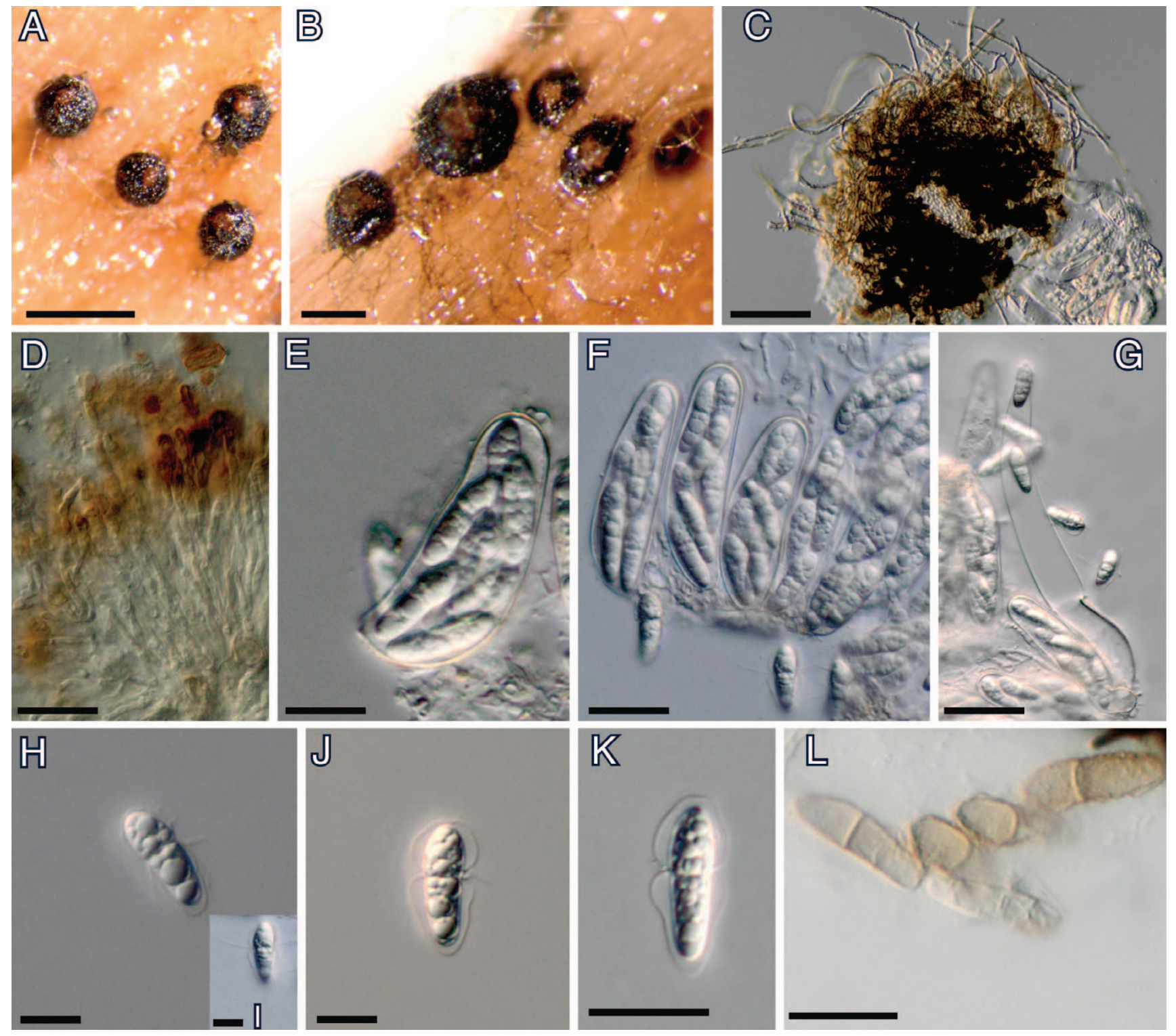

Fig. 5. Minutisphaera parafimbriatispora (From HOLOTYPE. G156-1). A, B. Ascomata on host surface. C. Squash mount of ascoma. D. Pseudoparaphyses. E, F. Asci. G. Fissitunicate ascus. H-J. Ascospores with gelatinous sheath and appendages radiating from the mid-septum. K. Ascospore with gelatinous sheath constricted at mid-septum. L. Senescent brown ascospores becoming rough-walled. Bars: $\mathrm{A}=200 \mu \mathrm{m} ; \mathrm{B}=100 \mu \mathrm{m} ; \mathrm{C}-\mathrm{G}, \mathrm{K}, \mathrm{L}=20 \mu \mathrm{m} ; \mathrm{H}-\mathrm{J}=10 \mu \mathrm{m}$.

on upper ascomal wall near the ostiole region (FIG. 5C). Hamathecium composed of sparse cellular pseudoparaphyses, interspersed tightly among asci, branched or unbranched; tips of pseudoparaphyses enlarged $(1-3 \mu \mathrm{m})$ and pigmented brown in apothecioid ascomata (FIG. 5D). Asci 48-72 $\times 15-22 \mu \mathrm{m}$ $($ mean and $\mathrm{SD}=63 \pm 5.7 \times 18 \pm 1.5 \mu \mathrm{m}, \mathrm{n}=30$ ) numerous, cymbiform to broadly clavate, fissitunicate, rounded and thickened at the apex, sessile, with eight biseriate ascospores (FIG. 5E-G). Ascospores 18-25 $\times$ 4-7 $\mu \mathrm{m}$ (mean and $\mathrm{SD}=22 \pm 1 \times 6 \pm 0.8 \mu \mathrm{m}, \mathrm{n}=$ 30 ), fusiform, multiguttulate, with a supramedian primary septum, slightly constricted at mid-septum, rounded at the apex, tapering toward the base, hyaline, one-septate when young, becoming brown, rough-walled, and three-septate with age; surrounded by a gelatinous sheath ca. $2 \mu \mathrm{m}$ wide at the ascospore base; sheath constricted at the mid-septum, with numerous, hyaline, filamentous appendages separating out of the sheath in water and radiating around the ascospore septum; appendages ephemeral, not visible in glycerin (FIG. 5H-L). Ascospores germinating from both apices.

Culture characters: Colonies on PDA 20-30 mm diam within $25 \mathrm{~d}$, surface uneven and velvet-like, light brown to smoke gray with an irregular margin. 
Anamorph: None observed.

Habitat: On submerged wood in a swamp.

Known distribution: USA (North Carolina).

Additional specimens examined: NORTH CAROLINA:

Rockingham County, Piedmont Plateau, 36 $27^{\prime} 42.1^{\prime \prime} \mathrm{N}$, $80^{\circ} 01^{\prime} 45.9^{\prime \prime} \mathrm{W}$, water $13 \mathrm{C}, \mathrm{pH}$ 5, Big Beaver Island Creek, Madison, on submerged decorticated wood, 26 April 2013, H.A. Raja and N.H. Oberlies G156-4, paratype: ILLS 72342; single ascospore culture, DSM 29480.

Notes: As the name suggests Minutisphaera parafimbriatispora is morphologically most similar to $M$. fimbriatispora. The major difference in morphology that separates the two species is ascospore size. The ascospores of $M$. parafimbriatispora are 18-25 $\times 4-7$ $\mu \mathrm{m}$ vs. $24-36 \times 6-8 \mu \mathrm{m}$ in the type species, $M$. fimbriatispora. Molecular phylogenetic analyses also support the finding that $M$. parafimbriatispora and $M$. fimbriatispora are different species (FIGS. 1-3).

Minutisphaera parafimbriatispora (G156-1) is morphologically similar to Minutisphaera sp. (G156-2; Raja et al. 2013b); however, ITS sequence data (FIG. 3) indicate that they are phylogenetically distinct. Additional collections of Minutisphaera spp. from North Carolina and further molecular sequencing are necessary to establish a new species for Minutisphaera sp. (G156-2). Results from studies thus far suggest evidence of cryptic speciation with respect to Minutisphaera sp. (G156-2).

Minutisphaera japonica Kaz. Tanaka, Raja \& Shearer Mycologia 105:966-969. 2013

Specimens examined: FRANCE, Ariège, Vernajoul, ruisseau de Vernajoul, ca. $500 \mathrm{~m}$ above Pont Fagé, $370 \mathrm{~m}$ elevation, on submerged wood of Fraxinus excelsior, 02 July 2007, Jacques Fournier, JF07132, associated with Pseudohalonectria lutea and Aniptodera sp., leg det JF; Ariège, Vernajoul, Vernajoul brook, Pont Fagé, 350 m elevation, submerged wood, 18 Jul 2013, Jacques Fournier, JF 13149 (ILLS 72436), JF 13160 (ILLS 72345); Ariège, La Maille brook, ca.550 m, submerged decorticated wood of Salix sp., 06 Apr 2008, Jacques Fournier, JF 08056.

Known distribution. France, Japan.

Notes: The specimens from France agree in all respects with the protolog of $M$. japonica (Raja et al. $2013 \mathrm{~b})$. In addition, a $28 \mathrm{~S}$ sequence of $M$. japonica from France (F 08056) grouped with the type of $M$. japonica with $88 \%$ RAxML BS (FIG.1).

Chemical study._-From the organic extract of liquid cultures of M. aspera (G427), five compounds were isolated and identified, of which four were the known dipeptides: cyclo-([S]-Pro-[S]-Leu) (1) (Adamczeski et al. 1995, Yang et al. 2009), cyclo-([R]-Pro-[S]-Phe) (2) (Bull et al. 1998), cyclo-([S]-Pro- $[S]$-Phe) (3) (Ott et al. 1963), and cyclo-([S]-Ala-[S]-Phe) (4) (Cho et al. 2012), and one the known aromatic polyketide

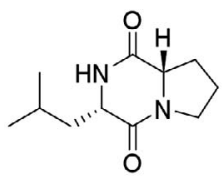

1

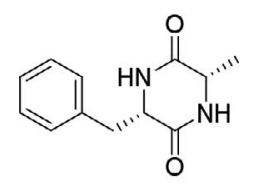

4

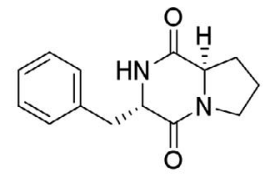

2

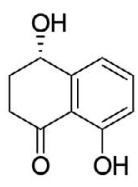

5

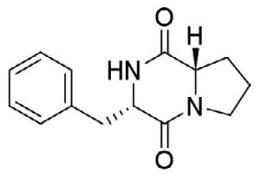

3

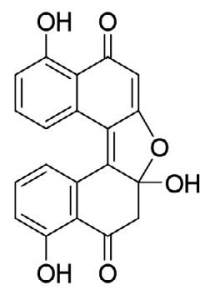

6
FIG. 6. Structure of compounds (1-6). cyclo-([S]Pro- $[S]-\mathrm{Leu})$ (1), cyclo-([R]-Pro- $[S]-\mathrm{Phe})$ (2), cyclo-([S]Pro-[S]-Phe) (3), cyclo-([S]-Ala-[S]-Phe) (4), polyketides isosclerone (5) and sphaerolone (6)

isosclerone (5) (Evidente et al. 2011). On the other hand, two known aromatic polyketides isosclerone (5) and sphaerolone (6) (Bode and Zeeck 2000) were isolated and identified from the solid cultures of $M$. parafimbriatispora (G156-4) (FIG. 6). The isolated compounds were identified with a set of spectroscopic and spectrometric techniques, including HRESIMS, NMR and optical rotation data, where appropriate, which compared favorably to those reported in the literature. The absolute configuration of the dipeptides (1-4) was determined by Marfey's analysis of the individual amino acids. The absolute configuration of 6 was not determined due to paucity of sample. The antimicrobial activity of compounds (1-6) was evaluated in an array of bacteria and fungi, including Staphylococcus aureus, Escherichia coli, Mycobacterium smegmatis, Candida albicans, Aspergillus niger. Compound 6 showed promising activity against $S$. aureus and M. smegmatis with MIC values of 30 and $60 \mu \mathrm{g} /$ $\mathrm{mL}$, respectively.

\section{DISCUSSION}

Ordinal placement of Minutisphaera within the Dothideomycetes. - The Minutisphaera clade is a monophyletic, strongly supported clade of freshwater Dothideomycetes (FIG. 1). Based on the morphological characters such as very small, globose to subglobose, ostiolate ascomata, septate pseudoparaphyses, fissitunicate, ovoid to obclavate asci and oneseptate, hyaline to brown ascospores with or without a sheath, Minutisphaera could be placed in the Pleosporales as defined by Zhang et al. (2012). The molecular phylogenetic analysis suggests that Minuti- 
sphaera has no relationship with members of the Pleosporales (Fig. 1). In Raja et al. (2013b) Minutisphaera was compared to taxa in the Patellariaceae, based on morphological characters such as superficial apothecioid ascomata and pseudoparaphyses with enlarged tips that closely overarch the asci as observed in M. japonica. However, based on molecular phylogenetic analysis, this hypothesis was refuted because Hysteropatella spp., which were included in the molecular phylogenetic analysis, did not share phylogenetic affinities with Minutisphaeraceae (FIG. 1). Farlowiella carmichaeliana, a species belonging to the Hysteriaceae (Boehm et al. 2009a, b) has a close, sister clade, phylogenetic relationship (100\% RAxML BS and $100 \%$ Bayesian PP) with members of the Minutisphaera (FIG. 2). This relationship has been revealed in taxonomic studies of Minutisphaera (Ferrer et al. 2011, Raja et al. 2013b). Minutisphaera and Farlowiella, however, are morphologically distinct; the ascomata are perithecioid or apothecioid in Minutisphaeria vs. hysterothecial in Farlowiella. A study on the freshwater Dothideomycetes (Shearer et al. 2014), which conducted a combined analysis of $18 \mathrm{~S}$ and $28 \mathrm{~S}$ for more than 200 taxa sampled from 24 families from seven orders, also showed that the strongly supported monophyletic Minutisphaera clade did not share molecular phylogenetic similarities with any of the sampled orders within the Dothideomycetes. Thus we establish a new order (Minutisphaerales) and family (Minutisphaeraceae) within the Dothideomycetes for this unique freshwater ascomycetes clade.

Morphological affinities of Alascospora evergladensis and Minutisphaera.-Alascospora evergladensis is a freshwater dothideomycete that was collected from submerged dead petioles of Nymphaea odorata during a survey of aquatic fungi along a phosphorus gradient in the Florida Everglades (Raja et al. 2010). This fungus is morphologically similar to the Minutisphaera in certain ascomatal and ascospore characters such as membranous, ostiolate ascomata with dark, amorphous material irregularly deposited on the peridium, especially around the ostiole, and oneseptate ascospores that are hyaline when young and surrounded by a hyaline gelatinous sheath. The original description of this fungus was based on morphological examination of the type specimen, but no sequences were generated at the time of its publication because the fungus could not be cultured. The dark amorphous material deposited around the ostiole region of the ascomata has been described as curved, with black hairs around the ostiole in the type description of $M$. fimbriatispora (Ferrer et al. 2011) and as curved, dark brown to black hyphal-like structures around the ostiole (this study). These dark hypha-like structures are seen in ascomata of A. evergladensis as well as all species of Minutisphaera described thus far. This morphological character appears to be a homologous character for the Minutisphaeraeace, which also is phylogenetically informative. A molecular phylogenetic study by Miller and Huhndorf (2005) suggested that ascoma wall morphology is a better character than ascospore morphology alone in defining genera in the Sordariales; the dark hyphal-like structures seen on the ascomata in Minutisphaera may support their hypothesis for this Dothideomycetes genus as well. Based on these shared morphological characters, it is possible that $A$. evergladensis could share phylogenetic affinities with Minutisphaeraceae. Alascospora, however, differs from Minutisphaera in that a large wing-shaped gelatinous sheath surrounds the ascospores and it occurs on petioles rather than wood. The brownspored species described in Minutisphaera thus far are equipped with gelatinous sheaths that are either amorphous (M. japonica) or appressed (M. aspera). Molecular data are necessary to shed light on the phylogenetic relationships of these two freshwater Dothideomycetes.

Putative ecological role of Minutisphaera spp.-All currently described Minutisphaera spp. (M. fimbriatispora, M. japonica, M. aspera, M. parafimbriatispora) have been isolated from submerged wood in freshwater habitats (Ferrer et al. 2011, Raja et al. 2013b) suggesting that they play an ecological role in nutrient cycling and organic matter decomposition in freshwater habitats (Simonis et al. 2008). A BLAST query (Altschul et al. 1990) of newly sequenced ITS strains of $M$. aspera and $M$. parafimbriatispora in GenBank identified two ITS sequences (Pleosporales sp. 39g; JX244063, and Didymosphaeria sp. TS_04_050; HQ713763) as top BLAST matches with high coverage and percent identity values to Minutisphaera. Based on uncorrected p distances calculated in PAUP*, the two ITS strains were identical and shared 99\% sequence similarity with ITS sequences of $M$. aspera. Our phylogenetic analysis places these strains sister to M. aspera; clade D (FIG. 3). Pleosporales sp. 39g (JX244063) was isolated as a fungal endophyte from surface-sterilized roots of eastern cottonwood in USA (Populus deltoids) (Bonito et al. unpubl), while Didymosphaeria sp. TS_04_050 (HQ713763) was isolated as a fungal endophyte from roots of Picea abies from Muri, Switzerland (Brenn et al. 2008, Grunig et al. 2011). The high ITS sequence similarity between these fungal endophytes and M. aspera could imply that Minutisphaera may lead a dual life as saprobes on submerged wood as 
well as fungal endophytes inside the roots of trees. However, additional studies are warranted to test this ecological hypothesis (Selosse et al. 2008). Previous work on freshwater ingoldian hyphomycetes also indicates that ingoldian fungi are capable of living as saprobes on dead decaying leaf litter and as fungal endophytes in roots of several terrestrial plant spp. (Bärlocher 2006, Kohout et al. 2012).

Secondary metabolite chemistry.-To explore the chemical profile of this newly described order and family, chemical analysis of the organic extracts of the newly collected species (M. aspera, M. parafimbriatispora) resulted in the isolation and characterization of six known secondary metabolites belonging to two structural classes, dipeptides and aromatic polyketides (FIG. 6). This is the first report of these secondary metabolites from freshwater fungi. Although the aromatic polyketide (isosclerone [5]) were isolated from the liquid and solid cultures of M. aspera and the solid cultures of $M$. parafimbriatispora, the dipeptides, cyclo-([S]-Pro-[S]-Leu) (1), Cyclo-([R]Pro- $[S]$-Phe) (2), cyclo-([S]-Pro- $[S]$-Phe (3) and cyclo-([S]-Ala- $[S]$-Phe) (4) were isolated only from the liquid cultures of $M$. aspera. These data offer insights in the interspecific variation of species in this new order and family of freshwater fungi. In our studies on $M$. parafimbriatispora (isolate G156-1a) (Raja et al. 2013b), two polyunsaturated fatty acids were the major metabolites. The richer chemical diversity observed in the current study further demonstrates the value of examining a variety of isolates and using a suite of growth conditions (Vandermolen et al. 2013). Additional chemical investigations from isolates of $M$. japonica might shed more light on this aspect. When evaluated for antimicrobial activity against an array of bacteria and fungi, compound 6 showed promising activity against $S$. aureus and $M$. smegmatis with MIC values of 30 and $60 \mu \mathrm{g} / \mathrm{mL}$, respectively. Because freshwater ascomycetes grow and reproduce on submerged wood in aquatic habitats where other bacterial species abound, these compounds might aid in defense from other microbial species. The secondary metabolite chemistry of Dothideomycetes has been reviewed (Muria-Gonzalez et al. 2014). Although much progress has been made in understanding the secondary metabolites of Dothideomycetes, little is known about the chemistry of freshwater Dothideomycetes. Families of freshwater Dothideomycetes such as Aliquandostipitaceae, Lindgomycetaceae and Natipusillaceae are virtually unsampled for secondary metabolites. Future studies, probing the chemistry and mycology in concert of this order, could uncover interesting chemical diversity.

\section{ACKNOWLEDGMENTS}

We thank Professor Joseph Falkinham III from Virginia Polytechnic Institute and State University for the antimicrobial testing. The authors from the University of North Carolina at Greensboro were supported in part by internal research and development funds. NHO and HAR thank David Sprinkle for letting them collect on his property and the city of Greensboro for permission to collect in Lake Brandt. We also thank the reviewers and the editors for their insightful suggestions that helped improve the manuscript. Financial support from the National Science Foundation (NSF Grant No. 08-44722) is greatly appreciated. Any opinions, findings and conclusions or recommendations expressed in this paper are those of the authors and do not necessarily reflect the views of the National Science Foundation.

\section{LITERATURE CITED}

Adamczeski M, Reed AR, Crews P. 1995. New and known diketopiperazines from the Caribbean sponge Calyx cf. podatypa. J Nat Prod 58:201-208, doi:10.1021/ np50116a007

Aguileta G, Marthey S, Chiapello H, Lebrun MH, Rodolphe F, Fournier E, Gendrault-Jacquemard A, Giraud T. 2008. Assessing the performance of single-copy genes for recovering robust phylogenies. Syst Biol 57:613627, doi:10.1080/10635150802306527

Altschul SF, Gish W, Miller W, Myers EW, Lipman DJ. 1990. Basic local alignment search tool. J Mol Biol 215:403410, doi:10.1016/S0022-2836(05)80360-2

Ayers S, Ehrmann BM, Adcock AF, Kroll DJ, Carcache de Blanco EJ, Shen Q, Swanson SM, FalkinhamIIIJO, Wani MC, Mitchell SM, Pearce CJ, Oberlies NH. 2012. Peptaibols from two unidentified fungi of the order Hypocreales with cytotoxic, antibiotic and anthelmintic activities. J Pept Sci 18:500-510, doi:10.1002/psc.v18.8

Bärlocher F. 2006. Fungal endophytes in submerged roots. In: Schulz BJE, Boyle CJC, Sieber TN, eds. Microbial root rndophytes. Berlin, Heideberg: Springer. p 179190.

Bode HB, Zeeck A. 2000. Sphaerolone and dihydrosphaerolone, two bisnaphthyl-pigments from the fungus Sphaeropsidales sp. F-24'707. Phytochem 54:597-601, doi:10.1016/S0031-9422(00)00145-X

Boehm EWA, Mugambi G, Miller AN, Huhndorf SM, Marincowitz S, Spatafora JW, Schoch CL. 2009a. A molecular phylogenetic reappraisal of the Hysteriaceae, Mytilinidiaceae and Gloniaceae (Pleosporomycetidae, Dothideomycetes), with keys to world species. Stud Mycol 64:49-83, doi:10.3114/sim.2009.64.03

-, Schoch CL, Spatafora JW. 2009b. On the evolution of the Hysteriaceae and Mytilinidiaceae (Pleosporomycetidae, Dothideomycetes, Ascomycota) using four nuclear genes. Mycol Res 113:461-479, doi:10.1016/ j.mycres.2008.12.001

Boonmee S, Rossman A, Liu J-K, Li W-J, Dai D-Q, Bhat J, Jones EBG, McKenzie EC, Xu J-C, Hyde K. 2014. Tubeufiales ord. nov., integrating sexual and asexual 
generic names. Fungal Divers 68:239-298, doi:10.1007/ s13225-014-0304-7

Brenn N, Menkis A, Grunig CR, Sieber TN, Holdenrieder O. 2008. Community structure of Phialocephala fortinii s. lat. in European tree nurseries and assessment of the potential of the seedlings as dissemination vehicles. Mycol Res 112:650-662, doi:10.1016/j.mycres.2007. 12.003

Bull SD, Davies SG, Parkin RM, Sánchez-Sancho F. 1998. The biosynthetic origin of diketopiperazines derived from D-proline. J Chem Soc Perkin1, 2313-2320, doi:10.1039/a802702a

Castresana J. 2000. Selection of conserved blocks from multiple alignments for their use in phylogenetic analysis. Mol Biol Evol 17:540-552, doi:10.1093/ oxfordjournals.molbev.a026334

Cho JY, Kang JY, Hong YK, Baek HH, Shin HW, Kim MS. 2012. Isolation and structural determination of the antifouling diketopiperazines from marine-derived Streptomyces praecox 291-11. Biosci Biotechnol Biochem 76:1116-1121.

Darriba D, Taboada GL, Doallo R, Posada D. 2012. jModelTest 2: more models, new heuristics and parallel computing. Nat Methods 9:772, doi:10.1038/nmeth. 2109

El-Elimat T, Raja HA, Day CS, Chen W-L, Swanson SM, Oberlies NH. 2014a. Greensporones: resorcylic acid lactones from an aquatic Halenospora sp. J Nat Prod 77: 2088-2098, doi:10.1021/np500497r

- - Figueroa M, FalkinhamIIIJO, Oberlies NH. 2014b. Isochromenones, isobenzofuranone and tetrahydronaphthalenes produced by Paraphoma radicina, a fungus isolated from a freshwater habitat. Phytochem 104:114-120, doi:10.1016/j.phytochem.2014.04.006

— Lucas DM, Grever MR, Wani MC, Pearce CJ, Oberlies NH. 2014c. Sorbicillinoid analogs with cytotoxic and selective anti-Aspergillus activities from Scytalidium album. J Antibiot 68:191-196.

Evidente A, Superchi S, Cimmino A, Mazzeo G, Mugnai L, Rubiales D, Andolfi A, Villegas-Fernández AM. 2011. Regiolone and isosclerone, two enantiomeric phytotoxic naphthalenone pentaketides: computational assignment of absolute configuration and its relationship with phytotoxic activity. Eur J Org Chem 5564-5570.

Fallah PM, Shearer CA. 2001. Freshwater ascomycetes: new or noteworthy species from north temperate lakes in Wisconsin. Mycologia 93:566-602, doi:10.2307/ 3761741

Felsenstein J. 1980. Confidence intervals on phylogenies: an approach using bootstrap. Evolution 39:1792-1797.

Ferrer A, Miller AN, Shearer CA. 2011. Minutisphaera and Natipusilla: two new genera of freshwater Dothideomycetes. Mycologia 103:411-423, doi:10.3852/10-177

Gardes M, Bruns TD. 1993. ITS primers with enhanced specificity for Basidiomycetes-application to the identification of mycorrhizae and rusts. Mol Ecol 2:113-118, doi:10.1111/j.1365-294X.1993.tb00005.x

Gouy M, Guindon S, Gascuel O. 2010. SeaView 4: a multiplatform graphical user interface for sequence align- ment and phylogenetic tree building. Mol Biol Evol 27: 221-224, doi:10.1093/molbev/msp259

Grunig CR, Queloz V, Sieber TN. 2011. Structure of diversity in dark septate endophytes: from species to genes. In: Pirttila AM, Frank AC, eds. Endophytes of forest trees: biology and applications. Springer. p 3-30.

Guindon S, Delsuc F, Dufayard JF, Gascuel O. 2009. Estimating maximum likelihood phylogenies with PhyML. Methods Mol Biol 537:113-37.

Hillis DM, Bull JJ. 1993. An empirical test of bootstrapping as a method for assessing confidence in phylogenetic analysis. Syst Biol 42:182-192, doi:10.1093/sysbio/ 42.2.182

Hirayama K, Tanaka K, Raja HA, Miller AN, Shearer CA. 2010. A molecular phylogenetic assessment of Massarina ingoldiana sensu lato. Mycologia 102:729-746, doi: 10.3852/09-230

Huelsenbeck JP. 2005. Bayesian analysis of molecular evolution using MrBayes. Statistical methods in molecular ecology. Springer. p 186-226.

— Ronquist F. 2001. MrBayes: Bayesian inference of phylogenetic trees. Bioinformatics 17:754-755, doi:10.1093/bioinformatics/17.8.754

Hyde KD, Jones EBG, Liu JK, Ariyawansa H, Boehm E, Boonmee S, Braun U, Chomnunti P, Crous PW, Dai DQ, Diederich P, Dissanayake A, Doilom M, Doveri F, Hongsanan S, Jayawardena R, Lawrey JD, Li YM, Liu YX, Lücking R, Monkai J, Muggia L, Nelsen MP, Pang KL, Phookamsak R, Senanayake IC, Shearer CA, Suetrong S, Tanaka K, Thambugala KM, Wijayawardene NN, Wikee S, Wu HX, Zhang Y, Aguirre-Hudson B, Alias SA, Aptroot A, Bahkali AH, Bezerra JL, Bhat DJ, Camporesi E, Chukeatirote E, Gueidan C, Hawksworth DL, Hirayama K, De Hoog S, Kang JC, Knudsen K, Li WJ, Li XH, Liu ZY, Mapook A, McKenzie EHC, Miller AN, Mortimer PE, Phillips AJL, Raja HA, Scheuer C, Schumm F, Taylor JE, Tian Q, Tibpromma S, Wanasinghe DN, Wang Y, Xu JC, Yacharoen S, Yan JY, Zhang M. 2013. Families of Dothideomycetes. Fungal Divers 63:1-313, doi:10.1007/s13225-013-0263-4

Inderbitzin P, Landvik S, Abdel-Wahab MA, Berbee ML. 2001. Aliquandostipitaceae, a new family for two new tropical ascomycetes with unusually wide hyphae and dimorphic ascomata. Am J Bot 88:52-61, doi:10.2307/ 2657126

Kohout P, Sykorova Z, Ctvrtlikova M, Rydlova J, Suda J, Vohnik M, Sudova R. 2012. Surprising spectra of rootassociated fungi in submerged aquatic plants. FEMS Microbiol Ecol 80:216-235, doi:10.1111/j.1574-6941. 2011.01291.x

Lutzoni F, Kauff F, Cox CJ, McLaughlin D, Celio G, Dentinger C, Padamsee M, Hibbett D, James TY, Baloch E, Grube M, Reeb V, Hofstetter V, Schoch C, Arnold AE, Miadlikowska J, Spatafora J, Johnson D, Hambleton S, Crockett M, Shoemaker R, Sung GH, Lücking R, Lumbsch T, O’Donnell K, Binder M, Diederich P, Ertz D, Gueidan C, Hansen K, Harris RC, Hosaka K, Lim YW, Matheny B, Nishida H, Pfister D, Rogers J, Rossman A, Schmitt I, Sipman H, Stone J, Sugiyama J, Yahr R, Vilgalys R. 2004. Assembling the 
fungal tree of life: progress, classification and evolution of subcellular traits. Am J Bot 91:1446-1480, doi:10.3732/ajb.91.10.1446

Miller AN, Huhndorf SM. 2005. Multigene phylogenies indicate ascomal wall morphology is a better predictor of phylogenetic relationships than ascospore morphology in the Sordariales (Ascomycota, Fungi). Mol Phyl Evol 35:60-75, doi:10.1016/j.ympev.2005.01. 007

Miller MA, Pfeiffer W, Schwartz T. 2010. Creating the CIPRES science gateway for inference of large phylogenetic trees., Proceedings of the Gateway computing environments workshop (GCE): 14 Nov 2010, p 1-8, New Orleans, Louisiana.

Muria-Gonzalez MJ, Chooi Y-H, Breen S, Solomon PS. 2014. The past, present and future of secondary metabolite research in the Dothideomycetes. Mol Plant Pathol 16: 92-107, doi:10.1111/mpp.2015.16.issue-1

Nylander JA, Wilgenbusch JC, Warren DL, Swofford DL. 2008. AWTY (Are we there yet?): a system for graphical exploration of MCMC convergence in Bayesian phylogenetics. Bioinformatics 24:581-583, doi:10.1093/ bioinformatics/btm 388

Ott H, Frey AJ, Hofmann A. 1963. The stereospecific cyclolization of $\mathrm{N}$-( $\alpha$-hydroxyacyl)-phenylalanyl-proline lactams. Tetrahedron 19:1675-1684, doi:10.1016/ S0040-4020(01)99240-3

Posada D, Buckley TR. 2004. Model selection and model averaging in phylogenetics: advantages of Akaike information criterion and bayesian approaches over likelihood ratio tests. Syst Biol 53:793-808, doi:10.1080/10635150490522304

Promputtha I, Miller AN. 2010. Three new species of Acanthostigma (Tubeufiaceae, Dothideomycetes) from Great Smoky Mountains National Park. Mycologia 102: 574-587, doi:10.3852/09-051

Raja HA, Oberlies NH, El-Elimat T, Miller AN, Zelski SE, Shearer CA. 2013a. Lindgomyces angustiascus (Lindgomycetaceae, Pleosporales, Dothideomycetes), a new lignicolous species from freshwater habitats in USA. Mycoscience 54:353-361, doi:10.1016/j.myc.2012. 12.004

__ _ - Figueroa M, Tanaka K, Hirayama K, Hashimoto A, Miller AN, Zelski SE, Shearer CA. 2013b. Freshwater ascomycetes: Minutisphaera (Dothideomycetes) revisited, including one new species from Japan. Mycologia 105:959-976, doi:10.3852/12-313

- Schoch CL, Hustad VP, Shearer CA, Miller AN. 2011. Testing the phylogenetic utility of MCM7 in the Ascomycota. Mycokeys 1:63-94, doi:10.3897/ mycokeys.1.1966

— Shearer CA. 2008. Freshwater ascomycetes: new and noteworthy species from aquatic habitats in Florida. Mycologia 100:467-489, doi:10.3852/07-167R

— cetes: Alascospora evergladensis, a new genus and species from the Florida Everglades. Mycologia 102: 33-38, doi:10.3852/09-096

Rambaut A, Drummond AJ. Tracer 1.5 Available from: http:/ / tree.bio.ed.ac.uk/software/tracer.
Rehner SA, Samuels GJ. 1995. Molecular systematics of the Hypocreales-a teleomorph gene phylogeny and the status of their anamorphs. Can J Bot 73:S816-S823, doi:10.1139/b95-327

Schmitt I, Crespo A, Divakar PK, Fankhauser JD, HermanSackett E, Kalb K, Nelsen MP, Nelson NA, Rivas-Plata E, Shimp AD, Widhelm T, Lumbsch HT. 2009. New primers for promising single-copy genes in fungal phylogenetics and systematics. Persoonia 23:35-40, doi:10.3767/003158509X470602

Schoch CL, Crous PW, Groenewald JZ, Boehm EWA, Burgess TI, de Gruyter J, de Hoog GS, Dixon LJ, Grube M, Gueidan C, Harada Y, Hatakeyama S, Hirayama K, Hosoya T, Huhndorf SM, Hyde KD, Jones EBG, Kohlmeyer J, Kruys А, Li YM, Lücking R, Lumbsch HT, Marvanová L, Mbatchou JS, McVay AH, Miller AN, Mugambi GK, Muggia L, Nelsen MP, Nelson P, Owensby CA, Phillips AJL, Phongpaichit S, Pointing SB, Pujade-Renaud V, Raja HA, Plata ER, Robbertse B, Ruibal C, Sakayaroj J, Sano T, Selbmann L, Shearer CA, Shirouzu T, Slippers B, Suetrong S, Tanaka K, Volkmann-Kohlmeyer B, Wingfield MJ, Wood AR, Woudenberg JHC, Yonezawa H, Zhang Y, Spatafora JW. 2009. A classwide phylogenetic assessment of Dothideomycetes. Stud Mycol 64:1-15, doi:10.3114/ sim.2009.64.01

, Robbertse B, Robert V, Vu D, Cardinali G, Irinyi L, Meyer W, Nilsson RH, Hughes K, Miller AN, Kirk PM, Abarenkov K, Aime MC, Ariyawansa HA, Bidartondo M, Boekhout T, Buyck B, Cai Q, Chen J, Crespo A, Crous PW, Damm U, de Beer ZW, Dentinger BTM, Divakar PK, Dueñas M, Feau N, Fliegerova K, García MA, Ge Z-W, Griffith GW, Groenewald JZ, Groenewald M, Grube M, Gryzenhout M, Gueidan C, Guo L, Hambleton S, Hamelin R, Hansen K, Hofstetter V, Hong S-B, Houbraken J, Hyde KD, Inderbitzin P, Johnston PR, Karunarathna SC, Kõljalg U, Kovács GM, Kraichak E, Krizsan K, Kurtzman CP, Larsson K-H, Leavitt S, Letcher PM, Liimatainen K, Liu J-K, Lodge DJ, Jennifer Luangsaard J, Lumbsch HT, Maharachchikumbura SSN, Manamgoda D, Martín MP, Minnis AM, Moncalvo JM, Mulè G, Nakasone KK, Niskanen T, Olariaga I, Papp T, Petkovits T, Pino-Bodas R, Powell MJ, Raja HA, Redecker D, Sarmiento-Ramirez JM, Seifert KA, Shrestha B, Stenroos S, Stielow B, Suh S-O, Tanaka K, Tedersoo L, Telleria MT, Udayanga D, Untereiner WA, Diéguez Uribeondo J, Subbarao KV, Vágvölgyi C, Visagie C, Voigt K, Walker DM, Weir BS, Weiß M, Wijayawardene NN, Wingfield MJ, Xu JP, Yang ZL, Zhang N, Zhuang W-Y, Federhen S. 2014. Finding needles in haystacks: linking scientific names, reference specimens and molecular data for Fungi. Database 2014.

, Seifert KA, Huhndorf S, Robert V, Spouge JL, Levesque CA, Chen W, Fungal Barcoding Consortium. 2012. Nuclear ribosomal internal transcribed spacer (ITS) region as a universal DNA barcode marker for Fungi. PNAS 109:6241-6246, doi:10.1073/pnas.11170 18109 
Selosse MA, Vohnik M, Chauvet E. 2008. Out of the rivers: Are some aquatic hyphomycetes plant endophytes? New Phytol, 178:3-7.

Shearer CA, Langsam DM, Longcore JE. 2004. Fungi in freshwater habitats. In: Mueller GM, Bills GF, Foster MS, eds. Measuring and monitoring biological diversity: standard methods for Fungi. Washington, D.C: Smithsonian Institution Press. p 513-531.

, Pang KL, Suetrong S, Raja HA. 2014. Phylogeny of the Dothideomycetes and other classes of freshwater fissitunicate Ascomycota. In: Gareth EBG, Hyde KD, Pang KL, eds. Freshwater fungi and fungal-like organisms. Berlin, Boston: de Gruyter. p 25-46.

, Raja HA. 2014. Freshwater Ascomycetes Database (http://fungi.life.illinois.edu/[Accessed Oct 2014].

, - - Miller AN, Nelson P, Tanaka K, Hirayama K, Marvanova L, Hyde KD, Zhang Y. 2009. The molecular phylogeny of freshwater Dothideomycetes. Stud Mycol 145-153.

Simonis JL, Raja HA, Shearer CA. 2008. Extracellular enzymes and soft rot decay: Are ascomycetes important degraders in freshwater? Fungal Divers, 31:135-146.

Stamatakis A. 2006. RAxML-VI-HPC: Maximum likelihoodbased phylogenetic analyses with thousands of taxa and mixed models. Bioinformatics 22:2688-2690, doi:10.1093/bioinformatics/btl446

Suetrong S, Boonyuen N, Pang KL, Ueapattanakit J, Klaysuban A, Sri-Indrasutdhi V, Sivichai S, Jones
EBG. 2011. A taxonomic revision and phylogenetic reconstruction of the Jahnulales (Dothideomycetes) and the new family, Manglicolaceae. Fungal Divers 51:163-188, doi:10.1007/s13225-011-0138-5

Swofford DL. 2002. PAUP* 4: phylogenetic analysis using parsimony (*and other methods), Sunderland: Massachusetts: Sinauer Associates.

Vandermolen KM, Raja HA, El-Elimat T, Oberlies NH. 2013. Evaluation of culture media for the production of secondary metabolites in a natural products screening program. AMB Express 3:71, doi:10.1186/2191-0855-3-71

Vilgalys R, Hester M. 1990. Rapid genetic identification and mapping of enzymatically amplified ribosomal DNA from several Cryptococcus species. J Bacteriol 172:42384246 .

White TJ, Bruns TD, Lee SH, Taylor JW. 1990. Amplification and direct sequencing of fungal ribosomal RNA genes for phylogenetics. In: Innis MA, Gefland, DH, Sninsky JJ, White TJ, eds. PCR protocols: a guide to methods and application San Diego, California: Academic Press. p 315-322.

Yang B, Dong J, Zhou X, Yang X, Kyung JL, Wang L, Zhang S, Liu Y. 2009. Proline-containing dipeptides from a marine sponge of a Callyspongia species. Helv Chim Acta 92:1112-1117, doi:10.1002/ hlca.v92:6

Zhang Y, Crous PW, Schoch CL, Hyde KD. 2012. Pleosporales. Fungal Divers 53:1-221, doi:10.1007/s13225-011-0117-x 